\title{
DOSSIER
}

\section{Rutas y travesías en el Caribe continental: historias de un territorio vacío}

Los textos reunidos en el Dossier El Caribe Continental desde Yucatán: nuevos paradigmas para el estudio de una región-frontera surgen de las discusiones realizadas durante 2017, en el "Seminario Permanente Estudios sobre el Caribe: Perspectivas transdisiciplinarias" que se lleva a cabo en la Universidad Autónoma de Yucatán, en el marco del proyecto de investigación "Representaciones literarias de insularidad en escritores de Yucatán, Belice y Guyana. Hacia un modelo para el Caribe continental" (Conacyt CB257673). Son los resultados de un empuje consolidado desde el Caribe colombiano y el Caribe yucateco con la posibilidad de abrir nuevos lugares de enunciación y miradas al área continental, que permitan -desde la historia, la geografía y los estudios culturales- profundizar en las definiciones y límites del espacio, los procesos de migración, y los procesos identitarios que trazan rutas a través del Caribe continental. Desde las costas e interiores de las áreas continentales se narran historias de conectividad, que evidencian un espacio diferenciado caracterizado por interacciones constantes y desiguales, trazos visibles y otros ocultos que acompañan su desarrollo como territorio caribeño desde tiempos de la conquista y colonia e incluso, desde antes.

Si bien los ensayos reunidos aquí afirman la existencia de un Caribe yucateco, y así mismo también construyen a nivel conceptual la idea de "los Caribes continentales", los debates nacionales (México) han tardado en entrar al diálogo con la propuesta de un Caribe continental desde la península de Yucatán. En México, los primeros estudios sobre el Caribe mexicano se realizaron a partir del puerto de Veracruz, en dos direcciones. En primer lugar, Veracruz como puerto comercial Atlántico -se dibuja el paralelo con Cartagena y más tardíamente con Barranquilla, en el Caribe colombiano. La actividad portuaria fijaba las 
rutas y conexiones con el llamado Golfo-Caribe, y Caribe Atlántico ${ }^{1}$. El segundo eje parte de Veracruz como centro afro-caribeño, diferenciando la región Golfo-Caribe de las áreas indígenas y mestizas de México para la afirmación de una identidad histórica y culturalmente diferente ${ }^{2}$. Al mirar a Yucatán desde Veracruz, se observaba una región indígena maya, sin presencia africana, que se alineaba con los discursos nacionales de mestizaje. No obstante, la mirada al Caribe desde la península de Yucatán (desde la orilla, y no desde el centro), permite entablar una discusión de los límites y márgenes del espacio Caribe. Los estudios sobre el Caribe en Yucatán son documentados en diversos estudios, como territorio estratégico en la zona desde la conquista ${ }^{3}$; o como espacio pendular, como cuasi-isla ${ }^{4}$ Las huellas ocultas de una presencia africana han sido evidenciadas en diversos estudios de Jorge Victoria Ojeda ${ }^{5}$, así como también las interacciones transfronterizas que marcan las redes y conectividad con el Caribe beliceño ${ }^{6}$, entre otros. La lectura de la península desde una lente Caribe permite entender la zona no solamente como un territorio con una población originaria maya, sino como un

1 Laura Muñoz, "El Golfo-Caribe, de límite a frontera de México", Historia Mexicana Vol. LVII, No. 2, (2007); Johanna Von Grafenstein, Antoinette Nelken y Laura Muñoz Mata, Un mar de encuentros y confrontaciones. El Golfo-Caribe en la historia nacional (México: Secretaría de Relaciones Exteriores, Dirección General del Acervo Histórico Diplomático, 2006).

2 Ricardo Pérez Montfort, Expresiones populares y estereotipos culturales en México, siglos XIX y XX: diez ensayos. (México: CIESAS, 2007); F. Ávila Domínguez, Ricardo Pérez Montfort y Cristian Rinaudo, Circulaciones culturales. Lo afrocaribeño entre Cartagena, Veracruz, y La Habana (México: Publicaciones de la Casa Chata, 2011; Antonio García de León, El mar de los deseos. El Caribe afroandaluz, historia y contrapunto (México: Fondo de Cultura Económica 2016).

3 Gabriel Macías Zapata, El vacío imaginario. Geopolítica de la ocupación territorial en el Caribe oriental mexicano (México: CIESAS 2004); Carlos Macías Richard El caribe mexicano. Origen y conformación, siglos XVI y XVII (Ciudad de México: Porrúa, 2006).

4 Margaret Shrimpton, Tejer historia en el Caribe. La narrativa yucateca contemporánea (La Habana/ Mérida: Editorial Artes y Letras/Universidad Autónoma de Yucatán, 2006); Margaret Shrimpton Masson, "Islas de tierra firme: ¿un modelo para el Caribe continental? El caso de Yucatán. Continental Islands: a model for the mainland Caribbean?", Memorias. Revista digital de historia y arqueología desde el Caribe colombiano Vol. 11, No. 25 (2015).

5 Jorge Victoria Ojeda, $(2014,2015)$ "Africanos y afrodescendientes en la Mérida de Yucatán, México. Dos apuntamientos (siglos XVI a XIX)”, Fronteras de la Historia, No. 19 (2014): 148-174; Jorge Victoria Ojeda, J y Aurelio Sánchez, "Interetnicidad y espacios de convivencia: españoles, indígenas y africanos en la Mérida novohispana, 1542-1620”, Secuencia, No. 92 (2015): 7-36.

146 Elizabeth Cunin, "Blackness and mestizaje: Afro-Caribbean music in Chetumal, Mexico". Latin American and Caribbean Ethnic Studies, Vol. 9, No. 1 (2014): 1-22; Ana Elvira Cervera Molina, (2017) "Fronteras, mapas e islas. La conformación de la frontera península de Yucatán-Belice. Una aproximación dialógica” (Tesis doctoral. El Colegio de Michoacán A.C, 2017). 
área étnicamente diversa, producto de constantes migraciones desde y hacia otros espacios del Caribe insular y continental. Carlos Macías (2006) traza cinco siglos de definiciones y delimitaciones del área $\mathrm{Ca}$ ribe y afirma la pertinencia de incluir no solamente las áreas de tierras firmes, sino también de considerar el rol de los pueblos originarios en la configuración del concepto Caribe:

"La evolución del concepto caribe a lo largo de cinco siglos se ha visto cometida a vaivenes en su connotación [...] de acuerdo con uno de los más influyentes cronistas tempranos (Gonzalo Fernández de Oviedo) la noción histórico-cultural de caribe comprende de manera central -a más de islas- a las costas de tierra firme (recuérdese el nombre de Caribana), al tiempo que enfatiza la noción temperamental de resistencia de los indígenas de la cuenca y de las islas"

Si bien la meta del Seminario era desde un principio mapear el Caribe en y desde Yucatán, esta cartografía requiere de la interacción con otros espacios continentales, que han llevado a evidenciar nexos y paralelos con el Caribe colombiano, entre otros. Compartimos desde Yucatán la afirmación de Vidal Ortega (desde el Caribe colombiano), y la importancia de mirar los bordes continentales del área no como límites sino como puntos de interacción: la mirada hacia la costa desde el interior y vice-versa, pone en evidencia los trazos de una vida articulada que genera nuevos paradigmas para definir un Caribe cuyas historias llenan los espacios vacíos que desde los discursos dominantes de Nación han imperado en la zona.

"En nuestros debates historiográficos en esta orilla del mar, comentamos reiteradamente que los historiadores de las islas, todavía tienen esa mirada sesgada de la región en su totalidad, pues en ocasiones no relacionan bien los procesos que se dieron en los bordes continentales, y consideran el Caribe tan solo en las islas. Procesos históricos que nos enlazan por vecindad y cercanía a pesar de que las rígidas historias na-

$7 \quad$ Carlos Macías Richard, El Caribe mexicano. Origen y conformación, siglos XVI y XVII (Ciudad de México: Porrúa, 2006), 258. 
cionales nos encerraron en estrechas fronteras imaginarias creadas en el Siglo XIX"».

La historia del espacio Caribe desde Yucatán se inscribe en este contexto de los territorios vacíos que explica Gabriel Macías Zapata como "El vacío imaginario" en su libro homónimo?. Una vez que nos permitamos volver a llenar el territorio, se vislumbran una serie de dinámicas que se asocian con los espacios fronterizos y marginados. Lejos de ser espacios homogéneos, en ellos se manifiestan complejas articulaciones y matices, que de cierta manera se vuelven más intrincadas y opacas en la medida que avancen los discursos del vacío. Shrimpton ${ }^{10}$ identifica para la península de Yucatán la configuración del espacio como una serie de micro-espacios, operando como "islas rodeadas de selva" 11 , dentro de los territorios continentales del área Caribe; por su parte, Joaualt ${ }^{12}$ emplea el concepto de "traspaís", para visibilizar los espacios "ocultos" detrás de las costas caribeñas del territorio continental a partir de los mecanismos turísticos durante el siglo XXI, en la Riviera Maya. Comparten estos enfoques el interés no solamente en visibilizar los procesos cotidianos e identitarios hacia adentro del territorio, sino en construir un modelo epistemológico para su estudio. En el caso del Caribe colombiano, Vidal persigue preguntas similares en sus estudios sobre la zona oculta detrás de Santa Marta en el "otro" Caribe colombiano, una zona de lugares de límites difusos que se modificaban continuamente

8 Antonino Vidal Ortega, "De políticos, migrantes y economía de frontera en la costa Caribe de Colombia en el siglo XIX”. Caribbean Studies, Vol. 42, No. 1 (2014): 133).

9 Gabriel Macías Zapata, El vacío imaginario. Geopolítica de la ocupación territorial en el Caribe oriental mexicano (Ciuad de México: CIESAS, 2004).

10 Margaret Shrimpton Masson, "Islas de tierra firme: ¿un modelo para el Caribe continental? El caso de Yucatán. Continental Islands: a model for the mainland Caribbean?”, Memorias. Revista digital de historia y arqueología desde el Caribe colombiano Vol. 11, No. 25 (2015).

11 David González Vázquez en Margaret Shrimpton Masson, "Islas de tierra firme: ¿un modelo para el Caribe continental? El caso de Yucatán”, Memorias. Revista digital de historia y arqueología desde el Caribe colombiano Vol. 11, No. 25 (2015): 195.

12 Samuel Jouault, Ana García de Fuentes y Marcela Jiménez, "Larrière-pays touristique de Cancún Riviera Maya" en Tourisme, marges et périphéries, eds. Nicolas Bernard, Caroline Blondy y Phillippe Duhamel (Rennes: Presses Universitaires de Rennes, 2017); Samuel Jouault, Mayas d'hier et d'aujourd hui. Le ròle des sociétés locales dans le développement touristique. Rennes: Presses Universitaires de Rennes, 2018) 
producto de esfuerzos militares, misionales, tratados diplomáticos y de la acción silenciosa y perseverante de los pobladores de las fronteras ${ }^{13}$.

Uno de los resultados que surge de este proceso de diálogos e intercambios en torno a los Caribes continentales es no solamente comprender su relevancia o pertinencia propiamente como parte integral del área Caribe, sino, evidenciar visualmente una cartografía del área que dé cuenta de la conectividad entre costas e interiores y el alto grado de diferenciación y marginación entre los diversos espacios. Es decir, si pensamos en el Caribe continental mexicano y colombiano a partir de los grandes puertos como Veracruz, Cartagena y Barranquilla, su inserción a un Caribe insular es una natural consecuencia, que se evidencia en las rutas y circulaciones entre estos puertos con La Habana y Nueva Orleans, por ejemplo ${ }^{14}$. Pero si consideramos las zonas peninsulares y periféricas al extremo oriente en ambos casos (La Guajira y la Península de Yucatán), nos vemos con la necesidad de considerar no solamente aquel Caribe con una dinámica portuaria y comercial a gran escala, sino también un micro-espacio, un Caribe extra-límite, detrás de las fronteras que fueron trazadas desde la colonia. Tanto Yucatán como La Guajira, han existido "detrás" de y a espadas de, los discursos de un gran Caribe: son "tierras vacías" y desiertas, no obstante su posición geográfica que apuntala directamente hacia el Caribe insular y desde cuyos territorios se han emprendido durante siglos micro-comercio y micro-migraciones, travesías constantes de piratas y comercios clandestinos, trazando rutas y poblaciones hacia los interiores ${ }^{15}$.

Los cinco ensayos incluidos aquí ofrecen una cartografía transdisciplinaria del Caribe desde la península de Yucatán. El primer ensayo, de

13 Antonino Vidal Ortega, "Comercio y mercado regional en la gobernación de Santa Marta a finales del siglo XVIII; informe de Jose de Astigarraga (1789)", en, Entre lo legal, lo ilícito y lo clandestino. Prácticas comerciales y navegación en el Gran Caribe siglos XVII al XIX, coord. Johanna Von Grafestein, Rafal Reichert y Julio César Rodríguez Treviño.

14 Freddy Ávila Domínguez, Ricardo Pérez Montfort y Cristian Rinaudo, Circulaciones culturales. Lo afrocaribeño entre Cartagena, Veracruz, y La Habana (México: Publicaciones de la Casa Chata, 2011).

15 Fahyr Arroyo Méndez, "La dehiscencia de América Latina: Horizontes expectativos en "La increíble y triste historia de la cándida Eréndira y de su abuela desalmada" de Gabriel García Márquez". (Tesis de licenciatura en Literatura Latinoamericana. Universidad Autónoma de Yucatán, 2018). 
Ana Elvira Cervera Molina, "El bucanero reformado como creador de geografías: espacio y territorio en la costa peninsular yucateca" estudia la literatura de viajes de William Dampier, escrito hacia finales del siglo XVII. A través de los escritos de Dampier, se revela una representación de los espacios que configura un territorio dejado en el abandono y con una población maya volátil y casi inexistente. Es la representación de un paisaje de límites costeros, con un vacío al interior. Irónicamente, estos vacíos contrastan con el lujo de detalle que abunda en los documentos y las descripciones de Dampier. El estudio de estos textos arroja luz a un discurso construido a partir de la utilidad comercial de los espacios: lo que no servía en estos términos era descrito por Dampier como un vacío. Los textos de Dampier revelan una combinación poderosa: por un lado, la precisión etnográfica, producto del método de observación científica; y por el otro lado, se evidencian los intereses, el diseño de un proyecto imperial, que decide dejar en el vacío las áreas que no sean necesarias. Cervera explica desde el análisis del discurso de Dampier los fundamentos de la creación del "territorio vacío", que invisibiliza la población originaria maya y vuelve a insistir en el valor de las zonas costeras y las ciudades principales ${ }^{16}$.

El artículo de Samuel Jouault, "Las movilidades y prácticas turísticas, ¿criterios válidos para delimitar el Caribe continental? Reflexiones a partir del caso de Yucatán" ofrece una serie de definiciones del espacio Caribe y del Caribe continental, para aproximarse a una geografía del turismo que pudiera aportar una epistemología que permita comprender los límites de un Caribe dinámico. Utilizando el turismo como herramienta para cartografiar un espacio diferenciado tanto por lo preciso de sus geografías como por lo difuso de los imaginarios, identifica su capacidad como agente de transformación de espacios, así como también como prisma de observación desde las comunidades locales. Una geografía del turismo tiene implicaciones espaciales como las relaciones entre el turismo y la producción de espacios, de nuevas territorialidades,

16 Ana Elvira Cervera Molina, "El bucanero reformado como creador de geografías: espacio y territorio en la costa peninsular yucateca", Historia Caribe Vol. XV No. 37 (Julio-Diciembre 2020): 23-49. DOI: http://dx.doi.org/10.15648/hc.37.2020.3 
y en el caso de la península de Yucatán, ofrece una cartografía alterna del Caribe continental ${ }^{17}$.

Los siguientes dos ensayos ofrecen una historia de ausencias. El artículo de Jorge Victoria Ojeda, "Lo africano-afrocaribeño en la construcción y representación de la identidad yucateca como parte del Caribe continental. Notas de un reclamo inconsciente", aborda el juego de identidades en Yucatán a partir de los procesos de negación de lo afro-caribeño en la representación de identidad en Yucatán. Conjugando diversas fuentes Victoria afirma primero la presencia de una población africana y afro-caribeña en Yucatán, si bien no numerosa en comparación con el puerto de Veracruz, hubo una presencia notable desde la segunda mitad del siglo XVI en adelante. El estudio de Victoria parte de la aparente ausencia no solamente de una población afrodescendiente hoy, sino también de la desaparición identitaria de lo afrodescendiente en la configuración de la identidad yucateca durante el siglo XIX hasta el presente. El artículo de Victoria Ojeda pone en evidencia la presencia de lo afrocaribeño en lo lingüístico, en las prácticas culturales (gremios, cofradías), en las artes visuales e incluso en fotografías, evidencias que niegan el poder del discurso dominante del territorio vacío, o territorio blanqueado, y demuestran no solamente una presencia sino la continuidad de las herencias culturales durante siglos. Narrar la historia de las ausencias, contribuye no solamente a una visibilización de lo afrodescendiente sino también a incluirlo en la construcción de paradigmas identitarios en la región ${ }^{18}$.

El Dossier continúa con el artículo de Maricruz Castro Ricalde, “Opacidad y transparencia del Caribe en las representaciones de Yucatán. Dos casos de cultura visual". La autora analiza un corpus de textos visuales -las ilustraciones de los calendarios producidos entre las décadas de los cuarenta y cincuenta del siglo XX-para revelar de nuevo el juego

17 Samuel Jouault, "Las movilidades y prácticas turísticas ¿criterios válidos para delimitar el Caribe continental? Reflexiones a partir del caso de Yucatán”, Historia Caribe Vol. XV No. 37 (Julio-Diciembre 2020): 51-81. DOI:http://dx.doi.org/10.15648/hc.37.2020.4

18 Jorge Victoria Ojeda, "Lo africano-afrocaribeño en la construcción y representación de la identidad yucateca como parte del Caribe continental. Notas de un reclamo inconsciente", Historia Caribe Vol. XV No. 37 (Julio-Diciembre 2020): 83-118. DOI: http://dx.doi.org/10.15648/hc.37.2020.5 
de poderes a partir de la representación de identidad en Yucatán. Leído en conjunto con el artículo anterior, este ensayo permite comprender las articulaciones de una identidad configurada nuevamente desde las ausencias. Las ilustraciones analizadas eluden toda referencia al Caribe visible; un esfuerzo para deslindar la península de los vínculos con el área Caribe que en términos comerciales y culturales se practicaban con frecuencia. Desde los conceptos de transparencia y opacidad (Glissant), Castro Ricalde muestra cómo la configuración de la identidad apela a los códigos homogéneos exigidos por una "transparencia" que inmoviliza a través de estereotipos, a la vez que opaca los elementos ocultos, y a veces inconscientes que constituyen las prácticas cotidianas. La discusión de Castro Ricalde expone lo pertinente de una historia de ausencias (de transparencias y opacidades), dada la condición fronteriza de la península y las complejas articulaciones identitarias que configura y manifiesta la condición pendular que permite que Yucatán oscile entre costa y selva, y entre nación y región Caribe. Este trabajo demuestra también los numerosos actores quienes participan en la articulación de los procesos históricos y las representaciones ${ }^{19}$.

Esta colección cierra con el artículo de Margaret Shrimpton Masson, "Mapas textuales de la península de Yucatán en el Caribe Continental: narrativas de huracanes", que traza las rutas que bordean y atraviesa la zona, en un mapeo de la península como “zona de huracán”. La lectura del huracán como meta-narrativa proporciona un lenguaje para mirar, sonar y contar las historias, y contribuye un importante espacio lingüístico para la discusión de regiones como el Caribe, y específicamente, los Caribes continentales. El huracán se vislumbra como tropo que plasma en imágenes y relatos las experiencias vividas entre diversas comunidades y permite trazar rutas entre áreas costeñas y pueblos al interior, ofreciendo nuevos mecanismos para comprender a la región, desde el entorno natural. El abordaje de estos materiales, escritos en español y en maya, es orientado desde el marco de la ecocrítica en una postura que busca proporcionar nuevas maneras de leer los espacios sociales y su articulación constante e inextricable con la experiencia humana ${ }^{20}$.

19 Maricruz Castro Ricalde, "Opacidad y transparencia del Caribe en las representaciones de Yucatán. Dos casos de cultura visual”, Historia Caribe Vol. XV No. 37 (Julio-Diciembre 2020): 119-150 DOI: http://dx.doi.org/10.15648/hc.37.2020.6

20 Margaret Shrimpton Masson, "Mapas textuales de la península de Yucatán en el Caribe Continental: narrativas de huracanes", Historia Caribe Vol. XV No. 37 (Julio-Diciembre 2020): 151-192 DOI: http://dx.doi.org/10.15648/hc.37.2020.7 


\section{Mapa No. 1}

A Compleat map of the West Indies: containing the coasts of Florida, Louisiana, New Spain, and Terra Firma, with all the Islands. London: Laurie \& Whittle, 53 Fleet Street, 1794. [MN- 14-A-16].

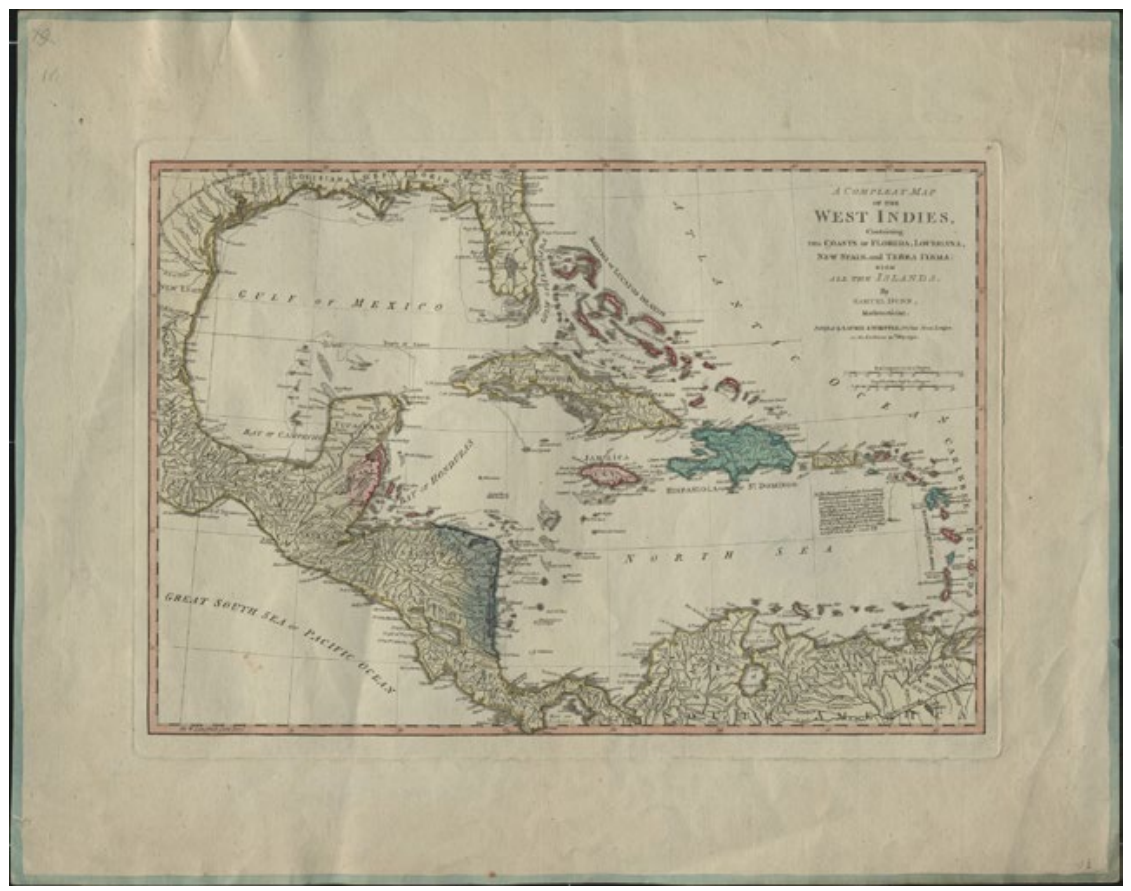

Fuente: Biblioteca Virtual del Ministerio de Defensa. España. http://bibliotecavirtualdefensa.es/BVMDefensa/i18n/ estaticos/contenido.cmd?pagina=estaticos/presentacion

\section{Margaret Shrimpton Masson}

Universidad Autónoma de Yucatán (México)

ORCID ID: orcid.org/0000-0002-0518-4326

\section{Antonino Vidal Ortega}

Pontificia Universidad Católica Madre y Maestra

(República Dominicana)

ORCID ID: orcid.org/0000-0002-0012-325X

DOI: https://doi.org/10.15648/hc.37.2020.2 